Provided for non-commercial research and education use. Not for reproduction, distribution or commercial use.

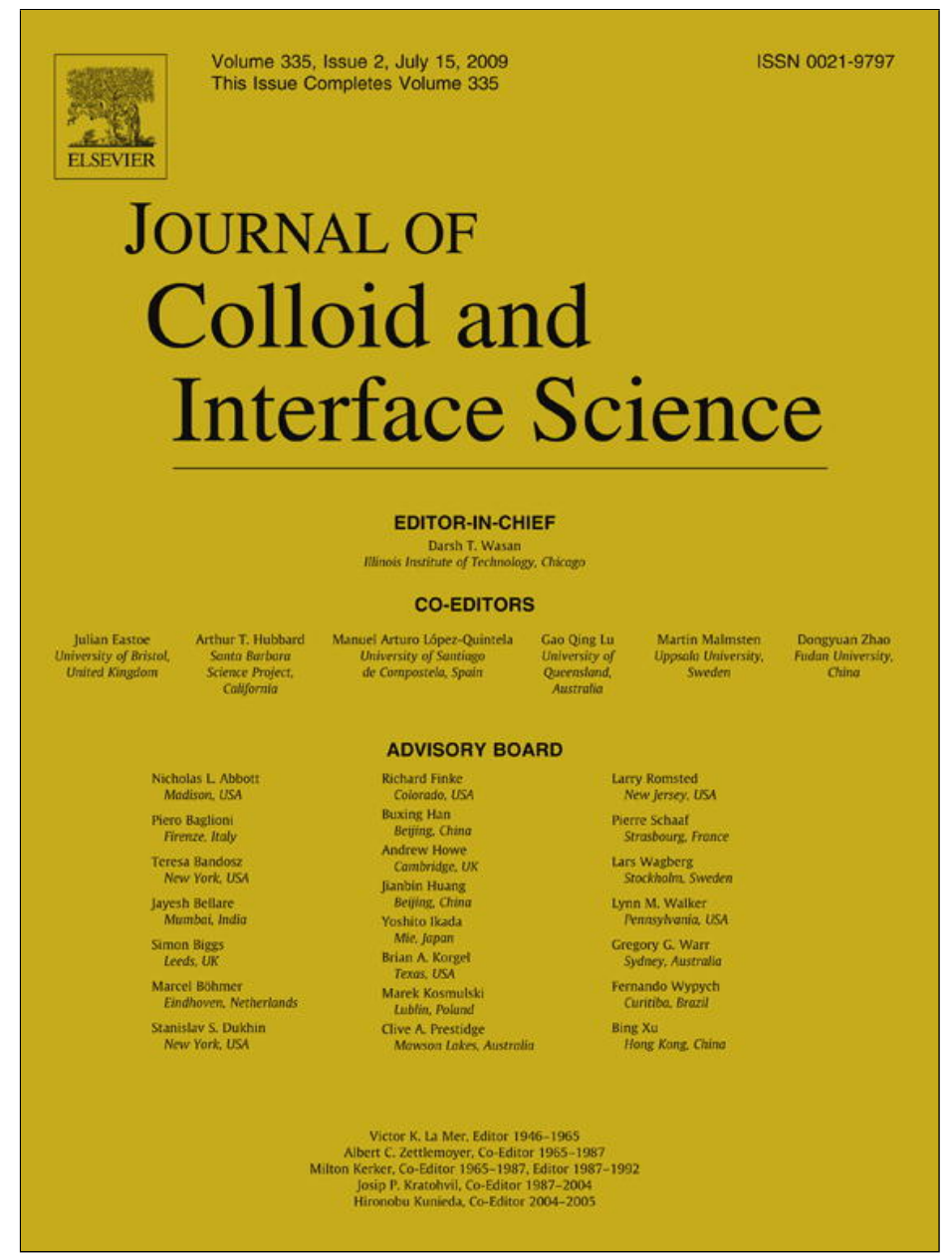

This article appeared in a journal published by Elsevier. The attached copy is furnished to the author for internal non-commercial research and education use, including for instruction at the authors institution and sharing with colleagues.

Other uses, including reproduction and distribution, or selling or licensing copies, or posting to personal, institutional or third party websites are prohibited.

In most cases authors are permitted to post their version of the article (e.g. in Word or Tex form) to their personal website or institutional repository. Authors requiring further information regarding Elsevier's archiving and manuscript policies are encouraged to visit:

http://www.elsevier.com/copyright 


\title{
Removal of phosphate from water by a Fe-Mn binary oxide adsorbent
}

\author{
Gaosheng Zhang ${ }^{\mathrm{a}, \mathrm{b}}$, Huijuan Liu ${ }^{\mathrm{a}}$, Ruiping Liu ${ }^{\mathrm{a}}$, Jiuhui $\mathrm{Qu}^{\mathrm{a}, *}$ \\ ${ }^{a}$ State key Laboratory of Environmental Aquatic Chemistry, Research Center for Eco-Environmental Sciences, Chinese Academy of Sciences, P.O. Box 2871, Beijing 100085, China \\ ${ }^{\mathrm{b}}$ Yantai Institute of Coastal Zone Research for Sustainable Development, Chinese Academy of Sciences, 26 Yinhai Rd, Yantai, 264003 Shandong, China
}

\section{A R T I C L E I N F O}

\section{Article history:}

Received 1 November 2008

Accepted 7 March 2009

Available online 31 March 2009

\section{Keywords:}

Fe-Mn binary oxide

Phosphate removal

Mechanism

Specific adsorption

\begin{abstract}
A B S T R A C T
Phosphate removal is important in the control of eutrophication of water bodies and adsorption is one of the promising approaches for this purpose. A Fe-Mn binary oxide adsorbent with a Fe/Mn molar ratio of 6:1 for phosphate removal was synthesized by a simultaneous oxidation and coprecipitation process. Laboratory experiments were carried out to investigate adsorption kinetics and equilibrium, in batch mode. The effects of different experimental parameters, namely contact time, initial phosphate concentration, solution $\mathrm{pH}$, and ionic strength on the phosphate adsorption were investigated. The adsorption data were analyzed by both Freundlich and Langmuir isotherm models and the data were well fit by the Freundlich isotherm model. Kinetic data correlated well with the pseudo-second-order kinetic model, suggesting that the adsorption process might be chemical sorption. The maximal adsorption capacity was $36 \mathrm{mg} / \mathrm{g}$ at $\mathrm{pH}$ 5.6. The phosphate adsorption was highly $\mathrm{pH}$ dependent. The effects of anions such as $\mathrm{Cl}^{-}, \mathrm{SO}_{4}{ }^{2-}$, and $\mathrm{CO}_{3}{ }^{2-}$ on phosphate removal were also investigated. The results suggest that the presence of these ions had no significant effect on phosphate removal. The phosphate removal was mainly achieved by the replacement of surface hydroxyl groups by the phosphate species and formation of inner-sphere surface complexes at the water/oxide interface. In addition, the adsorbed phosphate ions can be effectively desorbed by dilute $\mathrm{NaOH}$ solutions. This adsorbent, with large adsorption capacity and high selectivity, is therefore a very promising adsorbent for the removal of phosphate ions from aqueous solutions.
\end{abstract}

(c) 2009 Elsevier Inc. All rights reserved.

\section{Introduction}

As a main nutrient, phosphate is very essential for growth of organisms in most ecosystems. However, excessive amounts of phosphate supply to water bodies may cause eutrophication and subsequent deterioration of water quality $[1,2]$. In fact, the presence of trace amounts of phosphate (even less than $1 \mathrm{mg} / \mathrm{L}$ ) in the treated wastewater from municipalities and industries is often responsible for entrophication in receiving water bodies [3]. Therefore, removing phosphate is very necessary before discharging wastewater into water bodies.

Various techniques such as chemical precipitation [4], adsorption [5], reverse osmosis [6], biological removal [7,8], and constructed wetlands [9] have been employed for removal of phosphate from wastewaters. Among these available approaches, chemical precipitation and biological removal are generally not able to meet the stringent effluent standards and reverse osmosis is a high capital cost, while the adsorption methods proved to be more promising due to their low cost, effective treatment in dilute solutions, and high uptake capacity. Another attractive feature of

\footnotetext{
* Corresponding author. Fax: +861062923558.

E-mail addresses: gszhang@yic.ac.cn (G. Zhang), hjliu@rcees.ac.cn (H. Liu), liuruiping@rcees.ac.cn (R. Liu), jhqu@mail.rcees.ac.cn (J. Qu).
}

this technique is that the nutrient-loaded filters can be used in agriculture as phosphate fertilizer and soil conditioner [10]. A large number of materials from natural minerals to synthetic ones have been used as adsorbents to adsorb phosphate from wastewater [11-15]. Recently, the application of low cost and easily available materials for phosphate removal has been widely investigated, such as fly ash [16-18], blast furnace slag [19-21], iron oxide tailing [22], red mud [23,24], Ca-based adsorbents, and iron-based compounds [25-27].

Based on the risk of very dilute phosphate in water and more stringent effluent standards imposed, it is necessary to develop new adsorbents that are low cost, environmentally friendly, and effective for phosphate removal. Studies [28] have revealed that iron (hydr)oxides are effective for phosphate adsorption and play a major role in phosphate immobilization in water bodies and soils. Manganese oxides are also important scavengers of different anions such as phosphate in the freshwater and marine environment [29]. These two materials are both low cost and environmentally friendly. It can be anticipated that a Fe-Mn binary oxide originating from the combination of iron oxide and manganese dioxide will have the potential for phosphate removal.

However, up to now, no information is available on phosphate removal by $\mathrm{Fe}-\mathrm{Mn}$ binary oxides. In our laboratory, a series of Fe-Mn binary oxides with different Fe/Mn molar ratios (from 9:1 
to $1: 1$ ) were recently synthesized and were tested for phosphate removal. Preliminary results have shown that the Fe-Mn binary oxide with a Fe/Mn molar ratio of 6:1 was more effective for phosphate removal than other Fe-Mn binary oxides and pure amorphous $\mathrm{FeOOH}$ (details are presented in Supporting Material). Therefore, a Fe-Mn binary oxide with a Fe/Mn molar ratio of 6:1 was selected as potential adsorbent. This adsorbent was characterized with different techniques and the kinetics and isotherm of phosphate adsorption were studied. The influences of different experimental parameters such as solution $\mathrm{pH}$, ionic strength, and coexisting anions on phosphate removal as well as phosphate desorption were also investigated. Moreover, a phosphate adsorption mechanism is elucidated in the present paper.

\section{Materials and methods}

\subsection{Materials}

Fe-Mn binary oxide with a Fe/Mn molar ratio of 6:1 was prepared at room temperature $\left(25^{\circ} \mathrm{C}\right)$ in the laboratory, according to the following procedure: Potassium permanganate $\left(\mathrm{KMnO}_{4}\right.$, $2.37 \mathrm{~g}$ ) was dissolved in a $200 \mathrm{ml}$ of deionized water; ferric chloride $\left(\mathrm{FeCl}_{3} \cdot 6 \mathrm{H}_{2} \mathrm{O}, 12.16 \mathrm{~g}\right)$ and iron(II) sulfate heptahydrate (FeS$\mathrm{O}_{4} \cdot 7 \mathrm{H}_{2} \mathrm{O}, 12.51 \mathrm{~g}$ ) were dissolved in another $200 \mathrm{ml}$ of deionized water. Under vigorous magnetic stirring, the mixture solution of $\mathrm{FeCl}_{3}$ and $\mathrm{FeSO}_{4}$ was added into the $\mathrm{KMO}_{4}$ solution, and $5 \mathrm{M} \mathrm{NaOH}$ solution was simultaneously added to keep the solution $\mathrm{pH}$ in the range of 7-8. After addition, the formed suspension was continuously stirred for $1 \mathrm{~h}$, aged at room temperature for $4 \mathrm{~h}$, and then washed repeatedly with deionized water. The suspension was filtrated and dried at $60{ }^{\circ} \mathrm{C}$ for $24 \mathrm{~h}$. The dry material was crushed and stored in a desiccator for use. The obtained material appeared in the form of fine powder.

Potassium dihydrogen orthophosphate, sodium nitrate, sodium chloride, sodium sulfate, and sodium carbonate are all analytical grade and were purchased from Beijing Chemical Co. (Beijing, China). Phosphate solutions were prepared by dissolving the anhydrous potassium dihydrogen orthophosphate $\left(\mathrm{KH}_{2} \mathrm{PO}_{4}\right)$ in appropriate amounts of deionized water.

\subsection{Adsorbent characterization}

X-ray diffraction (XRD) analysis was carried out on a D/Max-3A diffractometer (Rigaku Co., Japan) using Ni-filtered copper $K \alpha 1$ radiation. The specific surface area was measured by nitrogen adsorption using the BET method with a Micromeritics ASAP 2000 (Micromeritics Co., USA) surface area analyzer. Particle size of the adsorbent was determined by a Mastersizer 2000 (Malvern Co.). The particle shapes were observed using a scanning electron microscope (SEM) with an EDAX KEVEX level 4 (Hitachi S-3500N).

FTIR spectra were collected on a Nicolet 5700 FTIR spectrophotometer (Nicolet Co., USA) using transmission model. Samples for FTIR determination were ground with spectral grade $\mathrm{KBr}$ in an agate mortar. IR spectra of phosphate adsorbed on the binary oxide were obtained as dry samples in $\mathrm{KBr}$ pellets corresponding to $5 \mathrm{mg}$ of sample in approximately $200 \mathrm{mg}$ of spectral grade $\mathrm{KBr}$. All IR measurements were carried out at room temperature.

A zeta potential analyzer (Zetasizer 2000, Malvern, UK) was used to analyze the zeta potential of Fe-Mn binary oxide particles before and after phosphate adsorption. The content of the Fe-Mn binary oxide in the solution was about $200 \mathrm{mg} / \mathrm{L}$ and phosphate concentration was $5 \mathrm{mg} / \mathrm{L}$. $\mathrm{NaNO}_{3}$ was used as background electrolyte to maintain an approximately constant ionic strength of $0.01 \mathrm{M}$. After mixing for $72 \mathrm{~h}$ to ensure the achievement of adsorption equilibrium, $20 \mathrm{ml}$ of oxide suspension was transferred to a sample tube. Zeta potential of the suspensions was then measured by electrokinetic analysis.

\subsection{Adsorption kinetics}

\subsubsection{Effect of contact time and initial phosphate concentration}

The kinetics experiments were carried out at room temperature $\left(25 \pm 1{ }^{\circ} \mathrm{C}\right)$. A defined amount of phosphate stock solution was added in a $1000-\mathrm{ml}$ glass vessel. Then, a corresponding amount of deioned water was added to make a $750 \mathrm{ml}, 5$ or $10 \mathrm{mg} / \mathrm{L}$ phosphate solution. The ionic strength was maintained as $0.01 \mathrm{M}$ by adding $0.638 \mathrm{~g}$ sodium nitrate. After the solution $\mathrm{pH}$ was adjusted to 6.9 by adding $0.1 \mathrm{M} \mathrm{HCl}$ and/or $\mathrm{NaOH}, 0.15 \mathrm{~g}$ of Fe-Mn binary oxide was added to obtain a $0.2 \mathrm{~g} / \mathrm{L}$ suspension. The suspension was mixed with a magnetic stirrer at an agitation speed of $140 \mathrm{rpm}$, and the $\mathrm{pH}$ was maintained at 6.9 throughout the experiment by addition of the dilute acid and/or base solutions. Approximately 5-ml aliquots were taken from the suspension at predetermined times. The samples were immediately filtered through a $0.45-\mu \mathrm{m}$ membrane filter. The concentrations of phosphate in the filtered solutions were determined using an inductively coupled plasma atomic emission spectroscopy (ICP-AES, SCIEX Perkin Elmer Elan Model 5000) at RF power of $1300 \mathrm{~W}$ and wavelength of $213.618 \mathrm{~nm}$. Prior to analysis, the aqueous samples were acidified with concentrated $\mathrm{HCl}$ in an amount of $1 \%$, and stored in acid-washed glass vessels. Finally, the exhausted adsorbent powders were taken out for further desorption study.

\subsubsection{Effect of $\mathrm{pH}$ and ionic strength}

To investigate the influence of $\mathrm{pH}$ and ionic strength on the phosphate adsorption, experiments were carried out by adding $10 \mathrm{mg}$ of the adsorbent sample into $150-\mathrm{ml}$ glass vessel, containing $50 \mathrm{ml}$ of $5 \mathrm{mg} / \mathrm{L}$ phosphate solution. The ionic strength of the solutions varied from 0.001 to $0.1 \mathrm{M}$ by adding $\mathrm{NaNO}_{3}$. The $\mathrm{pH}$ of the solutions was adjusted every $4 \mathrm{~h}$ with dilute $\mathrm{HCl}$ or/and $\mathrm{NaOH}$ solution to designated values in the range of 3-10 during the shaking process. The equilibrium $\mathrm{pH}$ was measured and the supernatant was filtered through a $0.45-\mu \mathrm{m}$ membrane after the solutions were mixed for $24 \mathrm{~h}$. Then, the residual phosphate concentration in the supernatant solutions was determined.

\subsubsection{Effect of coexisting anions}

The effect of common coexisting ions in wastewater such chloride, sulfate, and carbonate on the adsorption of phosphate was investigated by adding 1.0 or $10 \mathrm{mM}$ sodium chloride, sodium sulfate, and sodium carbonate to $5 \mathrm{mg} / \mathrm{L}$ of phosphate solution. The solution $\mathrm{pH}$ was adjusted to 5.6. A defined amount $(10 \mathrm{mg})$ of Fe-Mn binary oxide was added and the solutions were agitated at $140 \mathrm{rpm}$ for $24 \mathrm{~h}$ at $25 \pm 1{ }^{\circ} \mathrm{C}$. After filtration by a $0.45-\mu \mathrm{m}$ membrane filter, the residual concentration of phosphate was analyzed using ICP-AES.

\subsubsection{Desorption of phosphate}

For the study of desorption, the exhausted adsorbent powders were collected after filtration of the suspension from the above tests. Fifty milligrams of exhausted Fe-Mn binary oxide was added into each $150-\mathrm{ml}$ vessel containing $50 \mathrm{ml}$ solution with different concentrations of $\mathrm{NaOH}(0,0.001,0.01,0.1$, and $0.5 \mathrm{M})$. Appropriate $\mathrm{NaNO}_{3}$ was then added to adjust the ionic strength of the solution to $0.01 \mathrm{M}$. The solutions were agitated at $140 \mathrm{rpm}$ for $24 \mathrm{~h}$ at $25 \pm 1{ }^{\circ} \mathrm{C}$. The suspension solutions were then filtered and analyzed for phosphate according to the method described previously. The quantity of desorbed phosphate was determined by the amount of phosphate in the solution after the desorption experiment. The $\mathrm{P}$ desorbability was defined as the ratio of the desorbed $\mathrm{P}$ over the total $\mathrm{P}$ adsorbed by the adsorbent. 


\subsection{Adsorption isotherm}

Both Freundlich and Langmuir models [30,31] were employed to describe the experimental results of phosphate adsorption. The Freundlich equation is represented as

$q_{\mathrm{e}}=K_{\mathrm{F}} C_{\mathrm{e}}^{\mathrm{n}}$,

where $q_{\mathrm{e}}$ is the amount of phosphate adsorbed on the solid phase $(\mathrm{mg} / \mathrm{g}), C_{\mathrm{e}}$ is the equilibrium phosphate concentration in solution phase $(\mathrm{mg} / \mathrm{L}), K_{\mathrm{F}}$ is roughly an indicator of the adsorption capacity, and $n$ is the heterogeneity factor which has a lower value for more heterogeneous surfaces.

The Langmuir equation can be written in the form

$q_{\mathrm{e}}=q_{\mathrm{m}} \frac{K_{L} C_{e}}{1+K_{\mathrm{L}} C_{\mathrm{e}}}$,

where $q_{\mathrm{e}}$ and $C_{\mathrm{e}}$ are previously denoted, $K_{L}$ is the equilibrium adsorption constant related to the affinity of binding sites $(\mathrm{L} / \mathrm{mg})$, and $q_{\mathrm{m}}$ is the maximum amount of the phosphate per unit weight of adsorbent for complete monolayer coverage.

Phosphate adsorption isotherms were determined using bath tests at the initial $\mathrm{pH}$ values of $5.6 \pm 0.1$. Initial phosphate concentration was varied from 2 to $40 \mathrm{mg} / \mathrm{L}$. In each test, $10 \mathrm{mg}$ of the adsorbent sample was loaded in the $150-\mathrm{ml}$ glass vessel and $50 \mathrm{ml}$ of solution containing different amounts of phosphate was then added to the vessel. Ionic strength of the solution was adjusted to $0.01 \mathrm{M}$ with $\mathrm{NaNO}_{3}$. The vessels were shaken on an orbit shaker at $140 \mathrm{rpm}$ for $24 \mathrm{~h}$ at $25 \pm 1{ }^{\circ} \mathrm{C}$. After the reaction period, all samples were filtered by a $0.45-\mu \mathrm{m}$ membrane filter and analyzed for phosphate. The quantity of adsorbed phosphate was calculated by the difference of the initial and residual amounts of phosphate in solution divided by the weight of the adsorbent.

\section{Results and discussion}

\subsection{Properties of prepared Fe-Mn binary oxide}

An X-ray diffraction pattern of the synthesized Fe-Mn binary oxide is illustrated in Fig. 1. It shows the poorly ordered two-line ferrihydrite pattern with two broad peaks at $34.4^{\circ}$ and $62.1^{\circ}$, according to $d$ spacing of 0.260 and $0.149 \mathrm{~nm}$, respectively $[32,33]$. Thus, this oxide is thought to be amorphous.

The medium mass particle size of the powdered adsorbent was around $10-30 \mu \mathrm{m}$. The morphology and surface elements distribu-

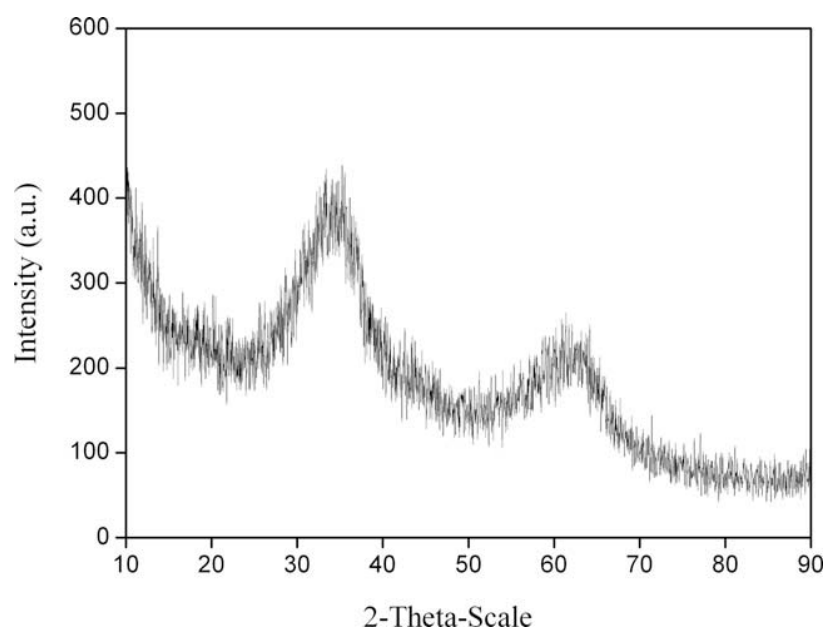

Fig. 1. XRD diffraction pattern of Fe-Mn binary oxide with a Fe/Mn molar ratio of $6: 1$. tion of the Fe-Mn binary oxide before and after phosphate adsorption were examined by a SEM combined to an EDAX KEVEX level 4. The image obtained showed that the adsorbent particles were aggregated with many nanoparticles (Fig. 2a), which resulted in a rough surface and porous structure. After phosphate adsorption, the morphology did not change significantly. EDX tests were carried out to obtain more specific results of homogeneous dispersion of iron and manganese for different sizes of particles. Chemical composition analysis (figures not presented) revealed that $\mathrm{Fe}$ and Mn were evenly distributed on the surface and the Fe/Mn molar ratio on the surface was in the range of 5.9-6.1, which is very close to the value of $6: 1$ of the bulk Fe/Mn molar ratio.

The material has a high BET specific surface area of $309 \mathrm{~m}^{2} / \mathrm{g}$ with a pore volume of $0.42 \mathrm{~cm}^{3} / \mathrm{g}$, which is in agreement with previous results $[32,34]$.

\subsection{Adsorption kinetics}

\subsubsection{Effect of contact time and initial phosphate concentration}

Kinetic experiments were performed to determine the rate of phosphate removal from the water by the Fe-Mn binary oxide. The initial phosphate concentrations were 5 and $10 \mathrm{mg} / \mathrm{L}$, respectively, and the initial $\mathrm{pH}$ value of solution was 5.6. Fig. 3 shows the change of adsorbed phosphate as a function of contact time. For initial concentration of $5 \mathrm{mg} / \mathrm{L}$, it is obvious that the adsorption process could be divided into two steps, a quick step and a slow one. In the first step, the adsorption rate was fast, and appropriate $87 \%$ of the equilibrium adsorption capacity was achieved within the beginning $2.5 \mathrm{~h}$. This may be due to the fine particles of FeMn binary oxide powders. The smaller particle size $(10-30 \mu \mathrm{m})$ was favorable for the diffusion of phosphate molecules from bulk solution onto the active sites of the solid surface. In the following step, intraparticle diffusion dominated and the adsorption slowed down. Another appropriate $10 \%$ removal percentage was observed with $8 \mathrm{~h}$. After $11 \mathrm{~h}$, over $98 \%$ of the maximum adsorption had taken place. The adsorption process of phosphate with an initial concentration of $10 \mathrm{mg} / \mathrm{L}$ is similar to that of $5 \mathrm{mg} / \mathrm{L}$, except for higher adsorption amounts. It could be also seen that the change of initial phosphate concentration did not significantly influence the equilibrium and $24 \mathrm{~h}$ was an adequate time for equilibrium to occur.

In order to evaluate the kinetic mechanism that controls the adsorption process. The experimental data (Fig. 3) were analyzed using Langergren pseudo-first-order model and pseudo-second-order model [35]. The kinetic parameters obtained from the models are given in Table 1. It is found that the kinetic data fitted well with the pseudo-second-order reaction rate model, which is evident from the higher correlation coefficient values. This study indicated that the pseudo-second-order model better represented the phosphate adsorption kinetics, suggesting that the adsorption process might be chemisorption.

\subsubsection{Effect of $\mathrm{pH}$ and ionic strength}

The results in Fig. 4 demonstrate the effects of $\mathrm{pH}$ and ionic strength on the adsorption of phosphate. As can be seen, the phosphate removal was evidently dependent on $\mathrm{pH}$ with the greatest adsorption occurring under acidic conditions and decreased with increase in solution $\mathrm{pH}$. Such $\mathrm{pH}$ effect has been observed for the sorption of phosphate onto iron oxides [36,37]. $\mathrm{H}_{2} \mathrm{PO}_{4}{ }^{-}$and $\mathrm{HPO}_{4}{ }^{2-}$ are dominant phosphate species in the solution under the tested $\mathrm{pH}$ range (3-10). Lower $\mathrm{pH}$ is favorable for the protonation of sorbent surface. Increased protonation is thought to increase the positively charged sites, enlarge the attraction force existing between the sorbent surface and the phosphate anions, and therefore increase the amount of adsorption in the lower $\mathrm{pH}$ region. In the higher $\mathrm{pH}$ region, the negatively charged sites dominate, the repulsion effect enhances, and the amount of adsorption 

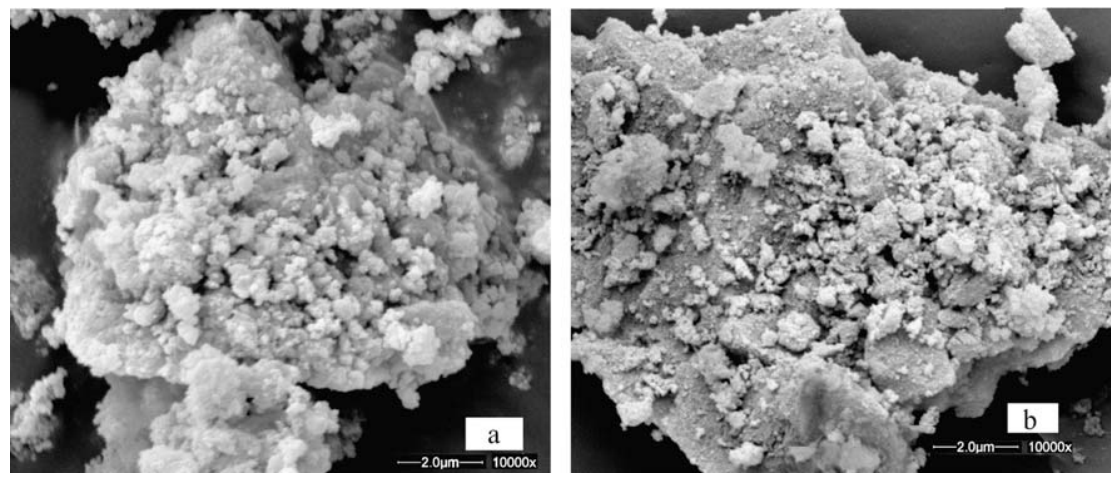

Fig. 2. SEM micrographs of Fe-Mn binary oxide particles (a) before and (b) after phosphate adsorption.

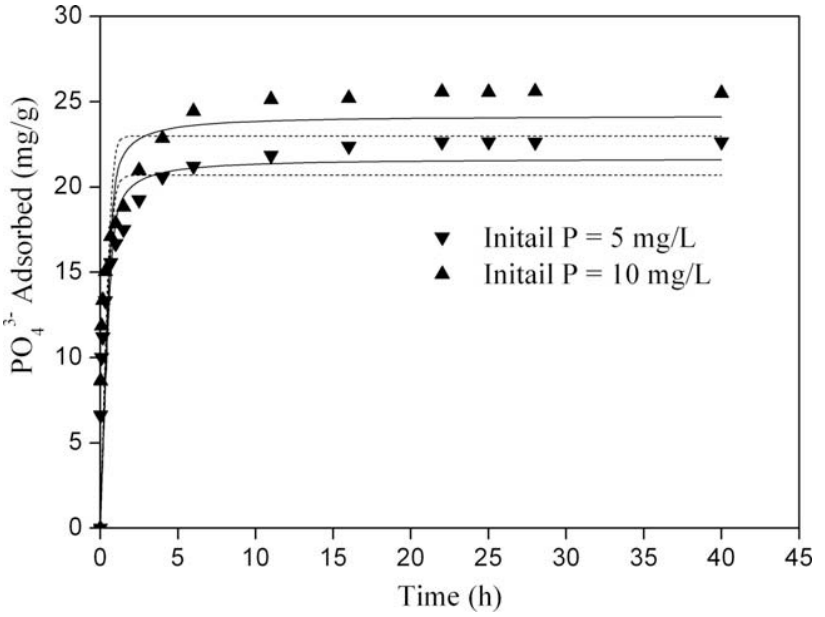

Fig. 3. The phosphate adsorption capacity of Fe-Mn binary oxide with the change of contact time at different initial concentrations. ( $\boldsymbol{\nabla}) 5 \mathrm{mg} / \mathrm{L},(\boldsymbol{\Lambda}) 10 \mathrm{mg} / \mathrm{L}$; nonlinear kinetic plots: $(\cdots)$ pseudo-first-order model, $(-)$ pseudo-second-order model; adsorbent dose $=200 \mathrm{mg} / \mathrm{L}, \mathrm{pH} 5.6$, particle size $=10-30 \mu \mathrm{m}$, agitation speed $=140 \mathrm{rpm}, T=25 \pm 1^{\circ} \mathrm{C}$.

Table 1

The kinetic model parameters for the adsorption of phosphate on Fe-Mn binary oxide at $\mathrm{pH}$ 5.6.

\begin{tabular}{|c|c|c|c|c|c|c|}
\hline \multirow{2}{*}{$\begin{array}{l}\text { Initial } \\
\text { concentration of } \\
\text { phosphate } \\
\left(\mathrm{mg} \mathrm{L}^{-1}\right)\end{array}$} & \multicolumn{3}{|c|}{$\begin{array}{l}\text { Pseudo-first-order } \\
\text { model } q_{\mathrm{t}}=q_{\mathrm{e}}\left(1-\mathrm{e}^{-k_{1} t}\right)\end{array}$} & \multicolumn{3}{|c|}{$\begin{array}{l}\text { Pseudo-second-order model } \\
q_{\mathrm{t}}=k_{2} q_{\mathrm{e}}^{2} t /\left(1+k_{2} q_{\mathrm{e}} t\right)\end{array}$} \\
\hline & $\begin{array}{l}q_{e} \\
\left(\mathrm{mg} \mathrm{g}^{-1}\right)\end{array}$ & $\begin{array}{l}k_{1} \\
\left(\mathrm{~h}^{-1}\right)\end{array}$ & $R^{2}$ & $q_{e}\left(\mathrm{mg} \mathrm{g}^{-1}\right)$ & $\begin{array}{l}k_{2} \\
\left(\mathrm{~g} \mathrm{mg}^{-1} \mathrm{~h}^{-1}\right)\end{array}$ & $R^{2}$ \\
\hline 5 & 20.69 & 4.05 & 0.847 & 21.68 & 0.287 & 0.931 \\
\hline 10 & 22.99 & 4.78 & 0.787 & 24.19 & 0.280 & 0.890 \\
\hline
\end{tabular}

is consequently dropped. In addition, the change of solution $\mathrm{pH}$ did not greatly alter the adsorption equilibrium time (seen in SI Fig. 2a).

It can also be seen that the increase in ionic strength from 0.001 to $0.1 \mathrm{M}$ led to a shift in the position of the $\mathrm{pH}$ edge toward the alkaline region, and also slightly enhanced the adsorption of phosphate in this range (7-10). A similar phenomenon was also observed by Giesler et al. using other metal oxides [38]. Anions that adsorb by outer-sphere association are strongly sensitive to ionic strength and the adsorption of these anions is suppressed by competition with weakly adsorbing anions such as $\mathrm{NO}_{3}{ }^{-}$since electrolytes also form outer-sphere complexes through electrostatic forces. Conversely, anions that adsorb by inner-sphere association either show little sensitivity to ionic strength or respond to higher ionic strength with greater adsorp-

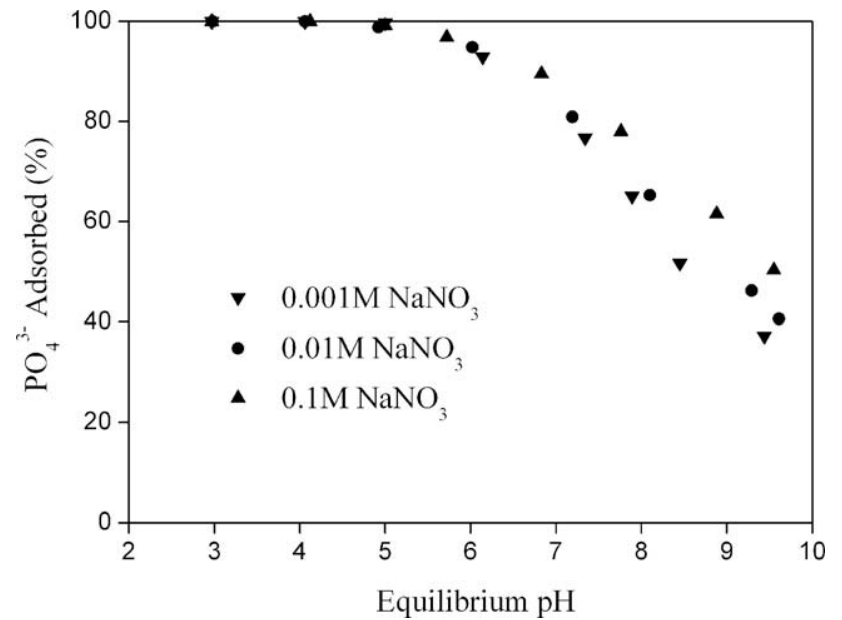

Fig. 4. Effect of $\mathrm{pH}$ and ionic strength on phosphate adsorption by Fe-Mn binary oxide. Initial $\mathrm{P}$ concentration $=5 \mathrm{mg} / \mathrm{L}$, adsorbent dose $=200 \mathrm{mg} / \mathrm{L}$, particle size $=$ $10-30 \mu \mathrm{m}$; agitation speed $=140 \mathrm{rpm}, T=25 \pm 1^{\circ} \mathrm{C}$.

tion [39]. Similarly, no obvious change of adsorption equilibrium time was observed with the change of ionic strength of solution (seen in SI Fig. 2b). The results of this experiment suggest that phosphate anions may form inner-sphere surface complexes at the water/oxide interface.

\subsubsection{Effect of coexisting anions}

Coexisting ions such as chloride, sulfate, and carbonate are generally present in the wastewater, and could interfere in the uptake of phosphate by adsorbent through competitive adsorption. Thus, the effects of these coexisting anions at two concentration levels $(1.0$ and $10 \mathrm{mM})$ on the phosphate removal were assessed at initial pH of 5.6 and the results are shown in Fig. 5. Only a slight decrease in phosphate removal was observed when the concentration of coexisting ions was increased from 1.0 to $10 \mathrm{mM}$. Obviously, the presence of these kinds of ions has no significant influence on the phosphate adsorption. This can be attributed to the specific adsorption of phosphate on the adsorbent because the phosphate ions adsorbed on the strong specific sites were rarely exchangeable even in a solution with a large excess amount of coexisting ions. This suggests that this oxide has high adsorption selectivity toward phosphate anions and has high potential to be used in real wastewater.

Moreover, the effect of present sulfate anions on the phosphate adsorption equilibrium was tested. The result is presented in SI Fig. 3 and it indicates that the presence of sulfate anions has no remarkable influence on equilibrium. 


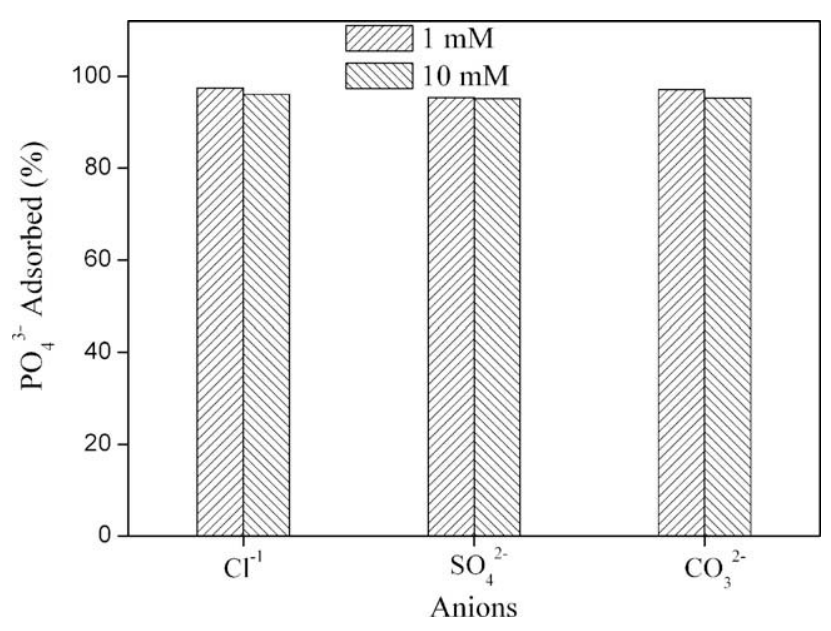

Fig. 5. Effect of coexisting anions on phosphate removal at fixed initial phosphate concentration $=5 \mathrm{mg} / \mathrm{L}$, adsorbent dose $=200 \mathrm{mg} / \mathrm{L}, \mathrm{pH} 5.6 \pm 0.1$, particle size $=10-$ $30 \mu \mathrm{m}$, agitation speed $=140 \mathrm{rpm}, T=25 \pm 1^{\circ} \mathrm{C}$, equilibrium time $=24 \mathrm{~h}$.

\subsubsection{Desorption of phosphate}

In the present study, the phosphate-loaded Fe-Mn binary oxide was desorbed using $\mathrm{NaOH}$ solutions of different concentrations. The results are presented in Fig. 6. It is clear that the amount of phosphate desorption increased with the increase of alkalinity. A desorption of only $0.6 \%$ was obtained when the extracting solution was only $0.01 \mathrm{M} \mathrm{NaNO}_{3}$ solution without added $\mathrm{NaOH}$. However, more than $93 \%$ of adsorbed phosphate was desorbed into the solution when the concentration of $\mathrm{NaOH}$ increased to $0.1 \mathrm{M}$. The further increase in $\mathrm{NaOH}$ concentration (up to $0.5 \mathrm{M}$ ) did not significantly enhanced the desorption of phosphate. It could be concluded that the adsorption of phosphate on Fe-Mn binary oxide is relatively reversible, and the bonding between the active sites and the adsorbed phosphate is not so strong. These results suggest that the phosphate-loaded material can be easily desorbed using a $0.1 \mathrm{M} \mathrm{NaOH}$ solution and has the potential to be used as an adsorbent for phosphate removal.

\subsection{Adsorption isotherm}

Isotherm studies were conducted to determine the maximum adsorption capacity of phosphate on Fe-Mn binary oxide from aqueous solution. Fig. 7 shows a plot of the uptake of phosphate

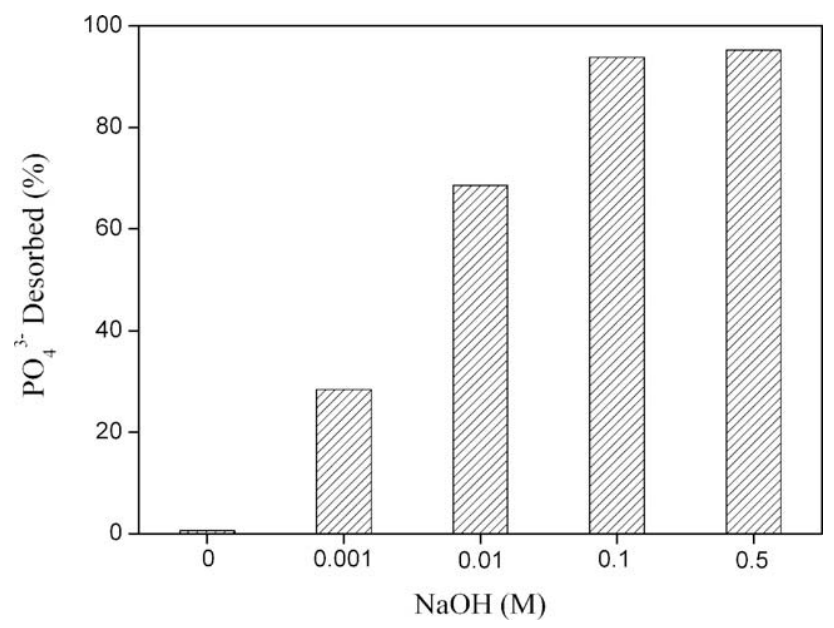

Fig. 6. Desorption of phosphate from P-loaded Fe-Mn binary oxide using different concentrations of $\mathrm{NaOH}$ solution at adsorbent dose $=1 \mathrm{~g} / \mathrm{L}$, agitation speed $=140 \mathrm{rpm}, T=25 \pm 1^{\circ} \mathrm{C}$, equilibrium time $=4 \mathrm{~h}$.

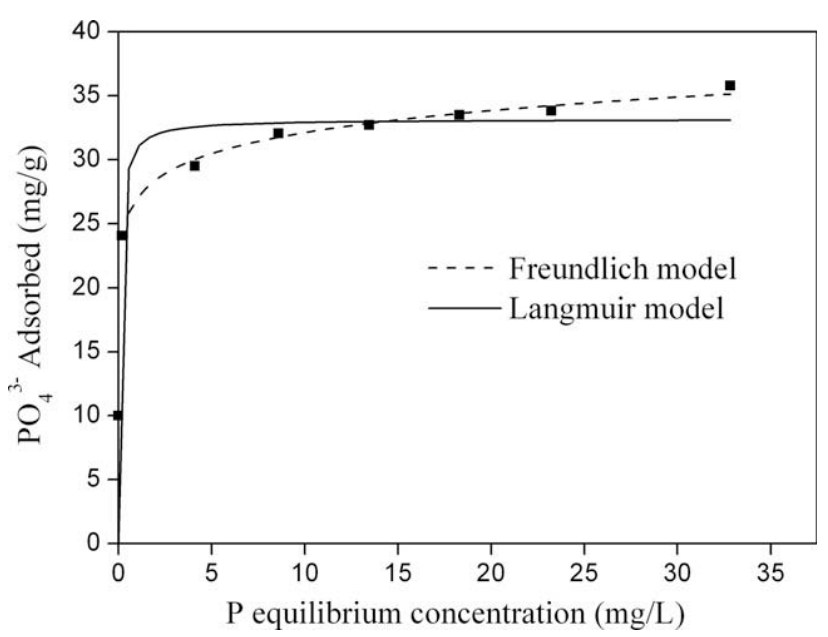

Fig. 7. Adsorption isotherm of phosphate by Fe-Mn adsorbent at pH $5.6 \pm 0.1$ and $T=25 \pm 1{ }^{\circ} \mathrm{C}$. (-) Langmuir model and (---) Freundlich model.

by the adsorbent against the phosphate equilibrium concentration in the solution. Both Langmuir and Freundlich equations were employed to describe the adsorption isotherm obtained in the figure. The adsorption constants obtained from the isotherm are listed in Table 2.

It is seen that the Freundlich model fitted the experimental data reasonably well. The value of correlation coefficient $\left(R^{2}>0.98\right)$, which is a measure of the goodness of fit, confirms the good representation of experimental data by this model. However, the Langmuir model was not suitable for describing the adsorption behavior of phosphate by Fe-Mn binary oxide, with a poor correlation coefficient $\left(R^{2}=0.76\right)$. It is not surprising that the Langmuir equation failed in describing the adsorption behavior of phosphate because this model assumes that adsorption occurs on a homogeneous surface. The presence of manganese dioxide in the adsorbent may lead to a more heterogeneous surface of solid. The Freundlich equation describes adsorption where the adsorbent has a heterogeneous surface with adsorption sites that have different energies of adsorption. Direct graphic maximal removal capacity (corresponding to the isotherm plateau) gives a maximal capacity of $36 \mathrm{mg}-\mathrm{P} / \mathrm{g}$. It is noted that this value is high as compared to the reported data in the literature; the maximum uptake is 1 and $7 \mathrm{mg}-\mathrm{P} / \mathrm{g}$ by blast furnace slag [21] and alkaline fly ash [18], respectively. From the isotherm, it could be also found that this adsorbent had a relative high adsorption capacity toward phosphate under low equilibrium concentration $(0.2 \mathrm{mg} / \mathrm{L})$. This indicates that the Fe-Mn binary oxide may be feasible for the removal of phosphate at a low concentration level. All these results suggest that the adsorbent may be used as an adsorbent for phosphate removal from wastewater, due to its high phosphate uptake, especially at low concentrations.

\subsection{Zeta potential and FTIR analysis}

Specific adsorption of anions makes the surface of oxides more negatively charged, which results in a shift of the isoelectric point of adsorbent to a lower $\mathrm{pH}$ value [40]. A lower isoelectric point of

Table 2

Langmuir and Freundlich isotherm constants for phosphate adsorption by Fe-Mn binary oxide at pH 5.6 and $T=25 \pm 1{ }^{\circ} \mathrm{C}$.

\begin{tabular}{lllllllll}
\hline Adsorbent & \multicolumn{2}{l}{ Langmuir model } & & \multicolumn{3}{l}{ Freundlich model } \\
\cline { 2 - 3 } & $q_{\mathrm{m}}\left(\mathrm{mg} \mathrm{g}^{-1}\right)$ & $K_{\mathrm{L}}\left(\mathrm{L} \mathrm{mg}^{-1}\right)$ & $R^{2}$ & & $K_{\mathrm{F}}$ & $n$ & $R^{2}$ \\
\hline Fe-Mn binary oxide & 33.2 & 13.62 & 0.762 & & 27.0 & 13.3 & 0.988 \\
\hline
\end{tabular}




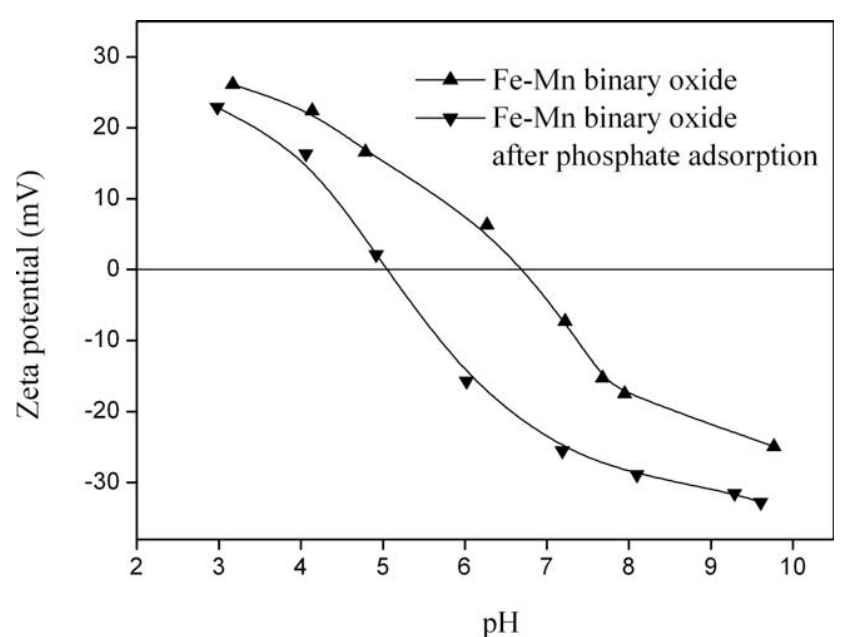

Fig. 8. Zeta potential of Fe-Mn binary oxide before and after phosphate adsorption at initial phosphate concentration $=5 \mathrm{mg} / \mathrm{L}$. Adsorbent dose $=200 \mathrm{mg} / \mathrm{L}$, ionic strength $=0.01 \mathrm{M} \mathrm{NaNO}_{3}$, equilibrium time $=72 \mathrm{~h}$.

the system should be therefore observed, if phosphate were specifically adsorbed on the Fe-Mn binary oxide. The zeta potentials of the Fe-Mn binary oxide suspensions before and after phosphate adsorption were measured and presented in Fig. 8. The Fe-Mn binary oxide was found to have an isoelectric point of about 6.6. As predicted, this value decreased to about 5.1 when phosphate anions were adsorbed. It is clear that the presence of phosphate anions makes the oxide surface more negatively charged. Specific adsorption rather than a purely electrostastic interaction could be deduced from the drop of isoelectric point at the aqueous phosphate/Fe-Mn binary oxide interface.

More useful information about the interaction between aqueous phosphate and solid Fe-Mn binary oxide can be provided by the FTIR technique. There are usually occurring metal hydroxyl groups on the surface of many metal oxides [41], which are the most abundant and active adsorption sites for adsorbate and can be detected by IR spectroscopy. IR spectroscopy has therefore been used to investigate the surface structures and the mechanism of adsorption.

The FTIR spectra of Fe-Mn binary oxide is obtained with the $\mathrm{KBr}$ pressed-disk technique and is shown in Fig. 9. For the Fe-Mn binary oxide sample, the band at $1625 \mathrm{~cm}^{-1}$ was assigned to the deformation of water molecules and indicated the presence of physisorbed water on the oxides; three peaks at 1123, 1051, and $974 \mathrm{~cm}^{-1}$ could be primarily attributed to the bending vibration of hydroxyl groups of iron (hydr)oxides ( $\mathrm{Fe}-\mathrm{OH}$ ) vibration [34].

FTIR spectra of the Fe-Mn binary oxide after reaction with phosphate solutions containing $1-40 \mathrm{mg} / \mathrm{L}$ of $\mathrm{P}$ at an initial $\mathrm{pH}$ of 6.9 for $24 \mathrm{~h}$ were collected and also shown in Fig. 9. After the oxide reaction with phosphate solution even at a concentration as low as $1 \mathrm{mg} / \mathrm{L}$, the $\mathrm{Fe}-\mathrm{OH}$ bending bands (peaks at 1123, 1051, and $974 \mathrm{~cm}^{-1}$ ) disappeared completely, while a new peak appeared at $1032 \mathrm{~cm}^{-1}$. This new band which is broad and intensive could be assigned to the asymmetry vibration of $\mathrm{P}-\mathrm{O}[28]$. This indicates that the surface hydroxyl groups were replaced by the adsorbed $\mathrm{PO}_{4}{ }^{3-}$. The intensity of this band increased obviously with the increase of $\mathrm{P}$ concentration. An increase in solution $\mathrm{pH}$ value was also observed after phosphate adsorption. From the FTIR and zeta analysis, it could be concluded that specific adsorption must occur at the aqueous phosphate/Fe-Mn binary oxide interface and the replacement of surface hydroxyl groups by the phosphate species is the main adsorption mechanism.

The possible reactions between the phosphate and the Fe-Mn binary oxide surface ( $\equiv \mathrm{S}-\mathrm{OH}$ ) could be presented as

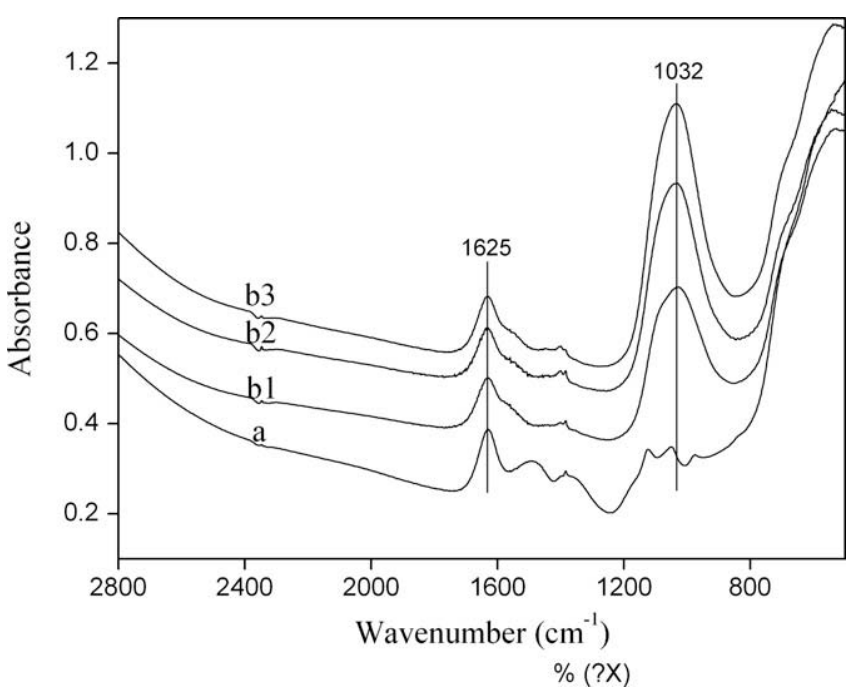

Fig. 9. FTIR spectra of Fe-Mn binary oxide (a) before and (b) after phosphate adsorption at different initial phosphate concentrations: b1 $=1 \mathrm{mg} / \mathrm{L}, \mathrm{b} 2=5 \mathrm{mg} / \mathrm{L}$, and b3 $=40 \mathrm{mg} / \mathrm{L}$. Equilibrium time $=24 \mathrm{~h}, \mathrm{pH} 6.9, T=25 \pm 1^{\circ} \mathrm{C}$.

$$
\begin{aligned}
& \equiv \mathrm{S}-\mathrm{OH}+\mathrm{PO}_{4}{ }^{3-}+\mathrm{H}^{+} \leftrightarrow \equiv \mathrm{S}-\mathrm{PO}_{4}{ }^{2-}+\mathrm{H}_{2} \mathrm{O} \\
& \equiv \mathrm{S}-\mathrm{OH}+\mathrm{PO}_{4}{ }^{3-}+2 \mathrm{H}^{+} \leftrightarrow \equiv \mathrm{S}-\mathrm{HPO}_{4}{ }^{-}+\mathrm{H}_{2} \mathrm{O} \\
& \equiv \mathrm{S}-\mathrm{OH}+\mathrm{PO}_{4}{ }^{3-}+3 \mathrm{H}^{+} \leftrightarrow \equiv \mathrm{S}-\mathrm{H}_{2} \mathrm{PO}_{4}+\mathrm{H}_{2} \mathrm{O} \\
& 2 \equiv \mathrm{S}-\mathrm{OH}+\mathrm{PO}_{4}{ }^{3-}+2 \mathrm{H}^{+} \leftrightarrow \equiv \mathrm{S}_{2}-\mathrm{PO}_{4}{ }^{-}+2 \mathrm{H}_{2} \mathrm{O}
\end{aligned}
$$

where $-\mathrm{OH}$ is a hydroxyl group.

\section{Conclusions}

A Fe-Mn binary oxide with Fe/Mn molar ratio of 6:1 was obtained by coprecipitation. The phosphate removal by this oxide was highly $\mathrm{pH}$ dependent and a maximal uptake was $36 \mathrm{mg}-\mathrm{P} / \mathrm{g}$ at $\mathrm{pH}$ 5.6. The adsorption of phosphate was slightly enhanced by an increase of ionic strength. The results of ionic strength test along with zeta potential and FTIR analysis indicate that phosphate anions may form inner-sphere surface complexes at the water/ oxide interface, which is the main phosphate removal mechanism. The oxide has high selectivity toward phosphate ions and coexisting anions such as chloride, sulfate, and carbonate did not greatly interfere in the uptake of phosphate. Adsorbed phosphate could be effectively desorbed by $0.1 \mathrm{M} \mathrm{NaOH}$ solution. This adsorbent, with large adsorption capacity and high selectivity, is a very promising adsorbent for the removal of phosphate ions from aqueous solutions.

\section{Acknowledgments}

This work was financially supported by the Funds for Creative Research Groups of China (Grant 50621804) and the National Natural Science Foundation of China (Grant 20577063). The authors are grateful to the reviewers for their good suggestions on revising the manuscript.

\section{Appendix A. Supplementary data}

Supplementary data associated with this article can be found, in the online version, at doi:10.1016/j.jcis.2009.03.019.

\section{References}

[1] W. Yao, F.J. Millero, Environ. Sci. Technol. 30 (1996) 536. 
[2] R. Chitrakar, S. Tezuka, A. Sonoda, K. Sakane, K. Ooi, T. Hirotsu, J. Colloid Interface Sci. 298 (2006) 602

[3] D. Zhao, A.K. Sengupta, Water Res. 32 (1998) 1613.

[4] D. Donnert, M. Salecker, Environ. Technol. 20 (1999) 735.

[5] S.-K. Kang, K.-H. Choo, K.-H. Lim, Sep. Sci. Technol. 38 (2003) 3853.

[6] E.M.v. Voorthuizen, A. Zwijnenburg, M. Wessling, Water Res. 39 (2005) 3657.

[7] J. De la Noüe, N. De Pauw, Biotechnol. Adv. 6 (1988) 725.

[8] L.E. de-Bashan, Y. Bashan, Water Res. 38 (2004) 4222

[9] D. Kurniadie, C. Kunze, J. Appl. Bot. 74 (2000) 87.

[10] L.D. Hylander, A. Kietlinska, G. Renman, G. Simán, Bioresour. Technol. 97 (2006) 914.

[11] A. Genz, A. Kornmuller, M. Kekel, Water Res. 38 (2004) 3523.

[12] K.M. Parida, S. Mohanty, J. Colloid Interface Sci. 199 (1998) 22

[13] E.W. Shin, J.S. Han, M. Jang, S.H. Min, J.K. Park, R.M. Rowell, Environ. Sci. Technol. 38 (2004) 912

[14] R.S.S. Wu, K.H. Lam, J.M.N. Lee, T.C. Lau, Chemosphere 69 (2007) 289.

[15] J.P. Gustafsson, A. Renman, G. Renman, K. Poll, Water Res. 42 (2008) 189

[16] A. Ugurlu, B. Salman, Environ. Int. 24 (1998) 911-918.

[17] D.G. Grubb, M.S. Guimaraes, R. Valencia, J. Hazard. Mater. 76 (2000) 217-236.

[18] K.C. Cheung, T.H. Venkitachalam, Chemosphere 41 (2000) 243.

[19] K. Sakadevan, H.J. Bavor, Water Res. 32 (1998) 393.

[20] L. Johansson, Sci. Total Environ. 229 (1999) 89.

[21] L. Johansson, J.P. Gustafsson, Water Res. 34 (2000) 259.
[22] L. Zeng, X.M. Li, J.D. Liu, Water Res. 38 (2004) 1318.

[23] G. Akay, B. Keskinler, A. Cakici, U. Danis, Water Res. 32 (1998) 717.

[24] S.B. Wang, H.M. Ang, M.O. Tadé, Chemosphere 72 (2008) 1621.

[25] M. Khadhraoui, T. Watanabe, M. Kuroda, Water Res. 36 (2002) 3711.

[26] Y. Seida, Y. Nakano, Water Res. 36 (2002) 1306

[27] O. Bastin, F. Janssens, J. Dufey, A. Peeters, Ecol. Eng. 12 (1999) 339.

[28] P. Persson, N. Nilsson, S. Sjöberg, J. Colloid Interface Sci. 177 (1996) 263.

[29] S. Mustafa, M.I. Zaman, S. Khan, J. Colloid Interface Sci. 301 (2006) 602.

[30] I. Langmuir, J. Am. Chem. Soc. 38 (1916) 2221.

[31] H.M.F. Freundlich, Z. Phys. Chem. 57 (1906) 385

[32] U. Schwertmann, R.M. Cornell, Iron Oxides in the Laboratory: Preparation and Characterization, second ed., Wiley-VCH, Weinheim, 2000.

[33] A. Hofmann, M. Pelletier, L. Michot, A. Stradner, P. Schurtenberger, R. Kretzschmar, J. Colloid Interface Sci. 271 (2004) 163.

[34] G.S. Zhang, J.H. Qu, H.J. Liu, R.P. Liu, R.C. Wu, Water Res. 41 (2007) 1921.

[35] S.M. Maliyekkal, A.K. Sharma, L. Philip, Water Res. 40 (2006) 3497.

[36] F.J. Hingston, A.M. Posner, J.L.J. Quirk, J. Soil Sci. 23 (1972) 177.

[37] J.C. Ryden, J.K.J. McLaughlin, J. Soil Sci. 28 (1977) 72.

[38] R. Giesler, T. Andersson, L. Lovgren, P. Persson, Soil Sci. Soc. Am. J. 69 (2005) 77

[39] M.B. McBride, Clays Clay Miner. 45 (1997) 598.

[40] T.H. Hsia, S.L. Lo, C.F. Lin, D.Y. Lee, Colloids Surf. A: Physicochem. Eng. Aspects. 85 (1994) 1.

[41] W. Stumm, Chemistry of the Solid-Water Interface, Wiley, New York, 1992. 